\title{
Continence and Complication Rates of Artificial Urinary Sphincter Devices (AMS 800) for Parkinson and Stroke Patients with Incontinence after Prostate Surgery: Retrospective Analysis of a Prospective Database
}

\author{
Valentin Maurer ${ }^{\mathrm{a}} \quad$ Justus Stahlberg ${ }^{\mathrm{a}}$ Insa Schiffmann ${ }^{\mathrm{b}} \quad$ Phillip Marks $^{\mathrm{a}}$ \\ Clemens M. Rosenbaum ${ }^{a}$ Armin Soave $^{a}$ Malte W. Vetterlein ${ }^{a}$ \\ Christian P. Meyer ${ }^{\mathrm{a}}$ Silke Riechardt ${ }^{\mathrm{a}} \quad$ Margit Fisch $^{\mathrm{a}} \quad$ Tim A. Ludwig $^{\mathrm{a}}$ \\ Roland Dahlem ${ }^{\mathrm{a}}$
}

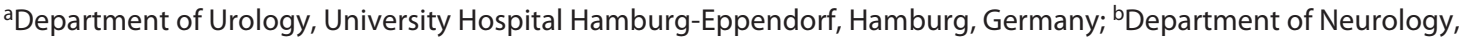
University Hospital Hamburg-Eppendorf, Hamburg, Germany

\begin{abstract}
Keywords
AMS 800 - Artificial urinary sphincter · Reconstructive urology · Stress urinary incontinence · Artificial urinary sphincter distal double cuff - Parkinson disease - Stroke . Neurourology
\end{abstract}

\begin{abstract}
Objectives: The artificial urinary sphincter (AUS) is the gold standard treatment for severe stress urinary incontinence (SUI). According to the literature, patients suffering from Parkinson's disease (PD) or stroke (ST) show adverse continence outcomes after prostate surgery and, therefore, constitute a challenging cohort for continence surgery. However, little is known with respect to the results of AUS surgery in these patients. A retrospective analysis of our institutional, prospectively maintained AUS database aims to address this aspect with a focus on surgical and functional outcomes. Methods and Patients: All data of patients with an AUS implantation were prospectively collected in our database
\end{abstract}

karger@karger.com

(c) 2021 S. Karger AG, Basel

www.karger.com/uin

Karger since 2009. The AUS was implanted according to a standardized protocol and activated at 6 weeks postoperatively at our institution. Further follow-up (FU) consisted of pad-test, uroflowmetry, residual urine, and radiography as well as a standardized questionnaire including the Incontinence Quality of Life questionnaire (I-Quol) and International Consultation on Incontinence questionnaire (ICIQ-SF) and is scheduled at 6 and 24 months and every 2 years thereafter. Patients received a preoperative urodynamic evaluation (UD). Patients with normal voiding and storage function were considered for AUS implantation. All patients performed a preoperative test for manual dexterity. Patients with a history of ST or PD were grouped and compared to nonneurological patients. Primary/secondary endpoints of the study were complications/continence. Results: 234 patients were available for analysis. The median FU was 24 months (interquartile range 7-36). Twenty-four patients (10\%) had a neurological history (PD and ST). Neurological patients showed significantly

Tim A. Ludwig and Roland Dahlem contributed equally.

Margit Fisch

Department of Urology, University Medical Center Hamburg-Eppendorf Martinistrasse 52

DE-20246 Hamburg (Germany)

m.fisch@uke.de 
worse outcomes regarding continence (objective/subjective/social continence; $p=0.04 / p=0.02 / p=0.1$ ). Significant differences concerning explantation rates were not observed $(p=1)$. Kaplan-Meier analysis showed no significant difference regarding explantation-free survival (log-rank $p=$ 0.53). Conclusion: AUS implantation shows significantly worse continence rates for neurological patients, despite the fact that all patients showed normal UD results and sufficient manual dexterity. Although neurological patients showed worse outcomes for continence, AUS implantation seems to be a safe and viable treatment for patients with a history of neurological disease.

(c) 2021 S. Karger AG, Basel

\section{Introduction}

Male urinary incontinence is an important complication in the realm of the operative treatment of prostate cancer and lower urinary tract symptoms. Incontinence rates from about $20 \%$ [1] up to $36 \% 1$ year after radical prostatectomy (RP) are described in the literature [2]. Late recovery rates after $\mathrm{RP}$ are about $40 \%$ after 24 months (m) and 50\% after $36 \mathrm{~m} \mathrm{[3].} \mathrm{According} \mathrm{to} \mathrm{the} \mathrm{current} \mathrm{Eu-}$ ropean Association of Urology (EAU) guidelines, the artificial urinary sphincter (AUS) constitutes the standard surgical treatment of severe stress urinary incontinence (SUI) [4].

The current body of literature outlines common risk factors associated with worse functional outcomes or failure after AUS implantation, such as diabetes mellitus, coronary artery disease, a history of pelvic radiation, or urethral/incontinence surgery $[5,6]$, which entail erosion, mechanical failure, or infection, all of which lead to revision surgery or to the explantation of the device. However, the aspect of functional outcomes of AUS implantations in patients with Parkinson's disease (PD) or stroke (ST) with a history of prostate surgery has been rarely discussed, despite the fact that urinary symptoms are frequently present over time in patients with a progressive neurological disease. A progress of the neurological disease over time is discussed to be potentially detrimental to the outcomes of incontinence surgery in these patients. Neurogenic overactive bladder as a manifestation of autonomic failure is the most common nonmotor symptom in patients with PD or ST $[7,8]$ and usually occurs after the onset of motor symptoms [9]. According to epidemiological studies, urinary symptoms are seen in $37-70 \%$ of PD patients [10] over time. Frequency, urgen$c y$, and urge incontinence are prevalent in $57-83 \%$ of PD patients [11]. 36-90\% of ST patients show detrusor muscle overactivity, and 7.5-40\% show detrusor hypoactivity 1 year after stroke [12]. Studies on the surgical and functional outcome after surgery in the lower urinary tract in the subset of neurological patients analyzed in this study are rare and ambiguous.

The EAU guidelines only mention that men who develop cognitive impairment or lose manual dexterity have more difficulties in operating an AUS [4]. The aim of the present study is to analyze AUS implantation as a treatment option for urinary incontinence after prostate surgery in patients with a history of PD or ST.

\section{Patients and Methods}

\section{Patient Population}

Since January 2009, in accordance with an Institutional Review Board approval, all perioperative and follow-up (FU) data of patients undergoing AUS implantation (American Medical Systems 800 ) at our institution have been prospectively collected in an AUS database. We included male patients with SUI level III-IV according to the definition of the international continence society [13]. Patients with detrusor overactivity or insufficient compliance apparent during the first $300 \mathrm{~mL}$ of bladder filling at urodynamic examination (UD) received a capacity training and, if necessary, an anticholinergic treatment or a treatment with botulinum toxin. Control-UDs were performed preoperatively. Those who were candidates for male sling implants (mild SUI and no history of radiation therapy) were excluded preoperatively. Moreover, patients who showed insufficient manual dexterity in the preoperative evaluation were excluded.

\section{Surgical Procedure}

The perioperative management was based on an institutional standardized protocol; each patient received perioperative intravenous antibiotic therapy (ceftriaxone and gentamicin). The AUSs were implanted according to standardized approaches [14] by high-volume surgeons.

In summary, a membranous single cuff (SC) was the approach of choice in patients with no history of radiation, erosion, infection, urethroplasty, or explantation. A distal double cuff (DC) was applied in case of a history of radiation, SC erosion, or infection. The AUS system was deactivated after the implantation, and a $12-\mathrm{F}$ transurethral catheter was placed and left in situ for 3 days after surgery. Postvoid residual urine measurements after catheter removal and radiological baseline studies were performed. The AUS was activated 6 weeks after implantation.

\section{Follow-Up}

FU was performed according to our institutional protocol. All patients were readmitted to our hospital 6 weeks after the AMS 800 implantation. After radiological imaging control of the sphincter device position, the AUS was activated under inpatient conditions and the patients were trained to operate the scrotal pump. Functional outcome was objectified by the stress pad test, uroflowmetry, postvoid urine measurement, and clinical examination. Further- 
Table 1. Clinical characteristics in patients treated by AUS implantation

\begin{tabular}{lccc}
\hline & $\begin{array}{l}\text { Neurological } \\
\text { cohort }\end{array}$ & $\begin{array}{l}\text { Nonneurological } \\
\text { cohort }\end{array}$ & $p$ value \\
\hline Patients, $n$ (\%) & $24(100)$ & $210(100)$ & - \\
Median age at surgery, years (IQR) & $71(69.0-74)$ & $70(65-74)$ & 0.25 \\
Median urine loss & $103(73-127)$ & $113(56-149)$ & 0.67 \\
$\quad$ Stress pad test, g (IQR) & $8(6.5-8.8)$ & $7(5-8)$ & 0.25 \\
$\quad$ Pads used/day, $n$ (IQR) & $3(2-3)$ & $2(2-3)$ & $\mathbf{0 . 0 2}$ \\
Median ASA classification (IQR) & $2(8.3)$ & $25(12)$ & $\mathbf{0 . 0 0 1}$ \\
Comorbidities/previous surgeries, $n(\%)$ & $17(71)$ & $72(34)$ & 0.30 \\
$\quad \begin{array}{l}\text { Diabetes mellitus } \\
\text { Anticoagulant therapy }\end{array}$ & $21(88)$ & $162(76)$ & 0.78 \\
Surgeries prior SUI, $n$ (\%) & $3(13)$ & $35(17)$ & 1 \\
$\quad$ Radical prostatectomy & 0 & $6(2.8)$ & 0.82 \\
$\quad$ TURP & $9(38)$ & $72(34)$ & 0.63 \\
$\quad$ Trauma & & $65(31)$ & 0.73 \\
Sxternal beam pelvic radiation therapy, $n(\%)$ & $5(21)$ & $58(52-69)$ & \\
$\quad \begin{array}{l}\text { Open surgical therapy for SUI } \\
\text { Median AUS operation time, minutes (IQR) }\end{array}$ & $58(49-63)$ & & \\
\hline
\end{tabular}

AUS, artificial urinary sphincter; IQR, interquartile range; ASA, American Society of Anesthesiologists; SUI, stress urinary incontinence. Results are significant with a significance level $p<0.05$.

more, a standardized, nonvalidated questionnaire consisting of the Incontinence Quality of Life questionnaire (I-Quol) and International Consultation on Incontinence questionnaire (ICIQ-SF) was administered. For long-term FU, patients were advised to return to our hospital at 6 and $24 \mathrm{~m}$ after surgery and every 2 years thereafter.

\section{Study Endpoint}

The primary endpoint of the study was the continence rate after AUS implantation. The level of SUI was assessed by the 1-h stress pad test (urine loss in grams) and the number of pads used per day. Objective continence or social continence was defined as the use of no pads or less than 2 pads per day, respectively. Subjective continence depended on patients' perception.

The secondary endpoint was the assessment of complication rates, with a particular focus on Clavien III complications (infection, erosion, mechanical failure, and consecutive explantation). The explantation-free survival was defined as patients without any need of explantation of the AUS during FU.

\section{Statistical Analyses}

For statistical analyses, associations between categorical variables were assessed using the $\chi^{2}$ test. Differences in variables with continuous distribution were assessed using the Mann-Whitney test. The probability of explantation-free survival was compared using Kaplan-Meier curves and the log-rank test between characteristic groups. Firth's penalized Cox regression analyses were performed to analyze proportional hazard ratios for AUS explantation. All tests were performed two-sided, and a $p<0.05$ was considered to be statistically significant. Statistical tests were performed with SPSS ${ }^{\circledR} 20$ (SPSS Inc., IBM Corp., Armonk, NY, USA) and R version 3.5.1 (The R Foundation).

Continence and Complication Rates of AUS Devices in Neurological Patients
Table 2. Complications

\begin{tabular}{lccc}
\hline & $\begin{array}{l}\text { Neurological } \\
\text { cohort }\end{array}$ & $\begin{array}{l}\text { Nonneurological } \\
\text { cohort }\end{array}$ & value \\
\hline Patients, $n(\%)$ & $24(100)$ & $210(100)$ & - \\
Infection (\%) & $0(-)$ & $8(3.8)$ & 1 \\
Erosion (\%) & $1(4.2)$ & $25(12)$ & 0.49 \\
Explantation (\%) & $4(17)$ & $38(18)$ & 1 \\
Mechanical failure (\%) & $1(4.2)$ & $7(3.3)$ & 0.58 \\
\hline
\end{tabular}

\section{Results}

\section{Patient Characteristics}

Patient characteristics are summarized in Table 1. Overall, 234 patients were analyzed. Twenty-four patients had a neurological history and were treated for PD or ST for at least 1 year. The median age at surgery was 70 years. Median urine loss before surgery was not significantly different between the neurological and the nonneurological cohort (103 g, interquartile range [IQR] 73127 vs. 113 g, IQR 56-149 g; $p=0.67$ ). There was no significant difference in pads used per day (8, IQR 7-9 vs. 7, IQR 5-8; $p=0.25)$. PD and ST patients showed a significantly worse American Society of Anesthesiologists 
Table 3. Means and medians for AUS explantation-free survival

\begin{tabular}{|c|c|c|c|c|c|c|c|c|}
\hline \multirow[t]{3}{*}{ Neurological } & \multicolumn{4}{|l|}{ Mean $^{a}$} & \multicolumn{4}{|l|}{ Median } \\
\hline & \multirow[t]{2}{*}{ estimate } & \multirow{2}{*}{$\begin{array}{l}\text { std. } \\
\text { error }\end{array}$} & \multicolumn{2}{|c|}{$95 \%$ confidence interval } & \multirow[t]{2}{*}{ estimate } & \multirow{2}{*}{$\begin{array}{l}\text { std. } \\
\text { error }\end{array}$} & \multicolumn{2}{|c|}{ 95\% confidence interval } \\
\hline & & & $\begin{array}{l}\text { lower } \\
\text { bound }\end{array}$ & $\begin{array}{l}\text { upper } \\
\text { bound }\end{array}$ & & & $\begin{array}{l}\text { lower } \\
\text { bound }\end{array}$ & $\begin{array}{l}\text { upper } \\
\text { bound }\end{array}$ \\
\hline No & 61 & 3.5 & 55 & 68 & 65 & 4,7 & 56 & 74 \\
\hline Yes & 62 & 5.6 & 51 & 73 & $*$ & $*$ & $*$ & $*$ \\
\hline Overall & 62 & 3.1 & 56 & 68 & 85 & 0.000 & $*$ & $*$ \\
\hline
\end{tabular}

AUS, artificial urinary sphincter. ${ }^{\text {a }}$ Estimation is limited to the largest survival time if it is censored. ${ }^{*}$ Not reached.

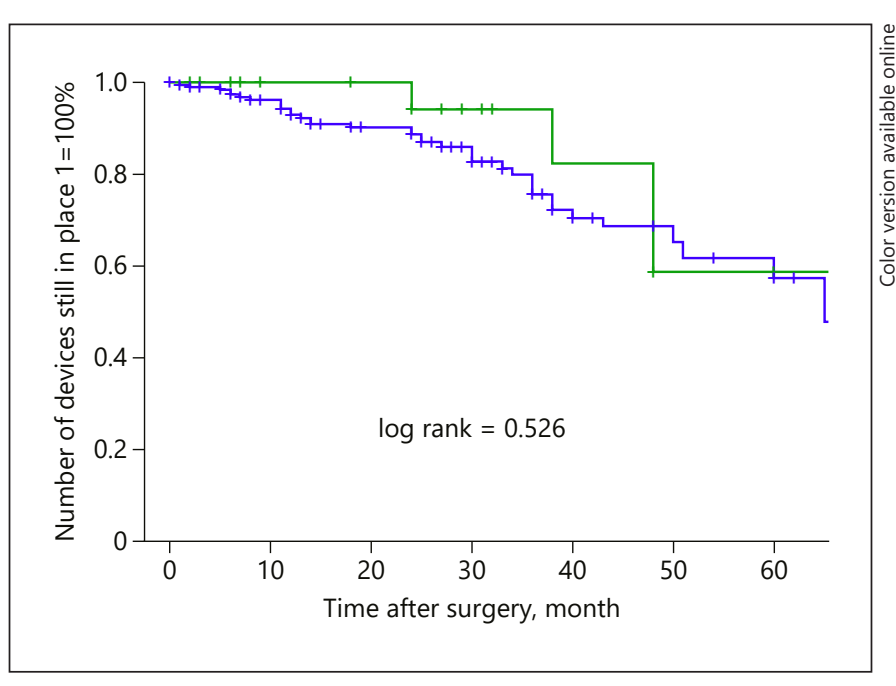

Fig. 1. Kaplan-Meier estimates of explantation-free survival after AUS implantation, neurological cohort (green) versus nonneurological cohort (blue). AUS, artificial urinary sphincter.

(ASA) status, which is used to assess a patient's operative risk (3, IQR $2-3$ vs. 2 , IQR $2-3$; $p=0.02$ ), and significantly more patients in the neurological cohort required anticoagulant therapy ( 71 vs. $34 \% ; p=0.001$ ). No significant differences are to be reported with respect to prior surgeries, such as RP ( 88 vs. $76 \%$; $p=0.30$ ), TURP (13 vs. $17 \%$; $p=0.78)$ or trauma surgery of the urethra ( 0 vs. $3 \%$; $p=$ 1 ), external beam pelvic radiation therapy (38 vs. $34 \%$; $p=0.824)$, or incontinence surgeries prior to AUS implantation ( 21 vs. $31 \% ; p=0.63)$. The median operation time was $58 \mathrm{~min}(\mathrm{~min})$ for both cohorts $(58 \mathrm{~min}$, IQR $49-63$ vs. $58 \mathrm{~min}$, IQR $52-69 \mathrm{~min} ; p=0.73$ ). In the nonneurological cohort, $65 \%$ of the patients had a DC and
$35 \%$ received an SC implantation. This is not significantly different to the neurological cohort with 59 and $41 \%$ having received a DC and SC, respectively $(p=1)$.

\section{Preoperative Urodynamic Evaluation of Neurological Patients}

Preoperative UD of PD and ST patients $(n=24)$ showed a median bladder volume of $367 \mathrm{~mL}$ (310-625 $\mathrm{mL}$ ). Eleven patients were treated with anticholinergic agents. Two patients received botulinum toxin bladder injections. All patients showed a stable detrusor at a volume of $300 \mathrm{~mL}$. At a volume of $>300 \mathrm{~mL}, 4$ patients (17\%) had a phasic detrusor overactivity. Compliance was $>20$ $\mathrm{mL} / \mathrm{cm} \mathrm{H}_{2} \mathrm{O}$ in all patients. The uroflowmetry showed no signs of a urethral stricture (median $Q_{\max } 22$ [IQR 18-29] $\mathrm{mL} / \mathrm{s}$ and 22 [IQR $17-31] \mathrm{mL} / \mathrm{s} ; p=0.70)$.

\section{Complication Rate and Functional Outcome}

Data (Table 2) on postoperative complications show that Clavien III complications, that is, infections and erosions, appeared in 4.2 and $0 \%$ of the neurological cases. There was 1 case of mechanical failure amongst neurological patients. The explantation rate in the neurological cohort was $17 \%$. These results were not significantly different from those of the nonneurological cohort.

The median FU was 24 m (6.5-36 m). In the KaplanMeier estimate, the calculated mean durability of the AUS was $61 \mathrm{~m}$ (54-68 m, confidence interval [CI] 95\%) in the nonneurological cohort compared to $62 \mathrm{~m}$ (51-73 m, CI $95 \%)$ in the neurological cohort (Table 3$)(p=0.53)$ (Fig. 1).

The objective, subjective, and social continence rates after $24 \mathrm{~m}$ median FU were assessed including only those patients whose AUS device was still in place at the time of 
Table 4. Functional outcome (all patients with devices still in place)

\begin{tabular}{llll}
\hline & $\begin{array}{l}\text { Neurological } \\
\text { cohort }\end{array}$ & $\begin{array}{l}\text { Nonneurological } \\
\text { cohort }\end{array}$ & $\begin{array}{l}p \\
\text { value }\end{array}$ \\
\hline Patients, $n(\%)$ & $20(100)$ & $172(100)$ & - \\
Objective continence, $n(\%)$ & $13(65)$ & $142(83)$ & $\mathbf{0 . 0 5}$ \\
Objective continence, $n(\%)$ & $13(65)$ & $142(83)$ & $\mathbf{0 . 0 5}$ \\
Subjective continence, $n(\%)$ & $14(70)$ & $154(90)$ & $\mathbf{0 . 0 2}$ \\
Social continence, $n(\%)$ & $17(85)$ & $185(95)$ & 0.12 \\
\hline
\end{tabular}

data collection ( $n=20$ for neurological and $n=172$ for nonneurological cohort) (Table 4). In this case objective, subjective and social continence for neurological patients were 65,70 , and $85 \%$, respectively. For the control group, objective, subjective, and social continence were 83,90 , and $95 \%$. Hence, objective and subjective continence were significantly worse for PD and ST patients $(p=0.05$; $p=0.02$ ). For social continence, a tendency for a worse continence outcome $(p=0.12)$ is to be seen. A longitudinal (max. $48 \mathrm{~m}$ ) analysis of pad usage in the neurological cohort showed no significant differences over time $(p=$ $0.06, p=0.07$, and $p=0.53$ for 6 weeks to $6 \mathrm{~m}, 6-24 \mathrm{~m}$, and $24-48 \mathrm{~m}$, respectively).

\section{Discussion}

Studies focusing on the treatment options of severe SUI in neurological patients with a history of prostate surgery are scarce. However, with an aging population and increasing number of prostate surgery being performed, the aspect of postoperative urinary incontinence treatment options in ST and PD patients will become increasingly relevant.

Studies on surgical and functional outcomes in PD patients after surgery of anatomic bladder outlet obstruction have shown de novo urge incontinence rates after TURP of up to $20 \%$ of the cases (the mean preoperative duration of PD before resection was 10 years; the mean FU was 9 months) [15]. Routh et al. showed that $24 \%$ of PD patients undergoing RP developed de novo incontinence (50\% urge, $25 \%$ mixed, and $25 \%$ stress) 1 year after surgery [13]. This may be explained by the fact that neurogenic overactive bladder usually occurs after motor symptoms $[7-9,16]$ over time and is seen in $37-83 \%$ of PD patients $[10,11]$ and deteriorates in accordance with the dopaminergic degeneration [17]. Detrusor overactivity is reported in $36-90 \%$ of ST pa-

Continence and Complication Rates of

AUS Devices in Neurological Patients tients 1 year after stroke [12]. Due to these functional impairments, patients suffering from PD or ST constitute a high-risk cohort for prostate surgery. As evidence on treatment options in these patients is low, management of postoperative incontinence in these cohorts remains uncertain.

Our data suggest that an AUS implantation is a safe and viable option for patients suffering from PD or ST (85\% social continence/65\% objective continence) and should be considered after careful patient selection and counseling. As PD or ST tend to go along with progressive motoric limitations, one might argue that worse continence outcomes in our neurological cohort may be explained by a progressive loss of manual dexterity. However, the hypothesis that insufficient manual operation subsequently leads to higher rates of system failure could be ruled out by our data, despite significantly worse ASA scores as well as a significantly higher percentage of anticoagulant therapy in the neurological cohort. Moreover, patients with deteriorating manual abilities should show rising levels of residual urine. In our analysis, neurological patients did not show significantly worse results with respect to postvoiding residual urine. Thereupon, our longitudinal analysis of pad usage in the neurological cohort showed no significant differences over time. However, the presented data have to be interpreted carefully, as the median FU was only $24 \mathrm{~m}$. An extended FU is required to further clarify this aspect.

In the current literature, it is also argued that bladder symptoms are only correlated with age [18]. This is not supported by our results. Within the neurological cohort, no correlation was to be seen between incontinence and age $(p=0.31)$ in our analysis.

Another explanation for worse objective and social continence outcomes in the neurological cohort is that a high percentage of PD and ST patients develop urgency over time, as outlined above $[10,11]$. However, this thesis cannot be proven on the grounds of our data, since FU UD evaluations have not been performed. In order to further examine this aspect, standardized FU UDs ought to be performed.

Preoperative UD is not established as a mandatory test in the current guidelines [4]. By contrast, the significance of preoperative UD in sphincter patients is discussed controversially in the current literature. A prospective cohort study by Trigo Rocha et al. [19] showed that from all urodynamic parameters assessed, only low bladder compliance had a negative impact on the outcome of AUS implantation. Preoperative urodynamic findings such as detrusor hyperactivity, impaired detrusor contraction, low 
Valsalva leak point pressure, bladder outlet obstruction, and mildly reduced bladder compliance were not associated with worse surgical outcomes [19]. A retrospective study by Lai et al. [20], including 129 patients suffering from prost-RP incontinence, of whom $34 \%$ were additionally treated by pelvic radiotherapy, showed that after a mean FU of 34 months, no urodynamic factors adversely altered the outcome of AUS implantation. However, the patients included in this study showed very inhomogeneous bladder dysfunctions. Moreover, an FU with respect to a careful observation of the upper urinary tract was not described in this study, despite the exposition of the upper urinary tract to a higher intravesical storage pressure. Also, Lai et al. [20] focused only on the aspect of continence, and complication rates were not taken into consideration - a crucial aspect with respect to long-term outcomes.

From our point of view, the preoperative UD and a careful evaluation of patients' characteristics on the grounds of preoperative questionnaires (I-Quol and ICIQ-SF) help to carefully identify those neurological patients suitable for an AUS in this particular challenging cohort. Furthermore, UD is particularly important in prostate cancer patients with a history of external beam irradiation therapy who encounter an increased risk for a reduced bladder capacity with a subsequently reduced compliance of the bladder.

Limitations of our study are that the median FU was only $24 \mathrm{~m}$. An extended FU is required in order to further verify the results and to analyze the underlying pathomechanism and to support the idea of a progressive development of an OAB.

Furthermore, the cohort consisted of only 24 patients due to a very strict preoperative selection, and only neurological patients with PD or ST were included. Younger patients with multiple sclerosis or spinal cord injury were not included in the neurological cohort. Moreover, due to the small size, it was not possible to perform subgroup analyses of PD or ST only.

\section{Conclusion}

AUS implantation shows significantly worse objective and social continence rates for neurological patients despite the fact that all patients showed normal UD results and sufficient manual dexterity in the preoperative evaluation. Neurological patients ought to be counseled accordingly. Nevertheless, AUS implantation seems to be a safe and viable treatment option for patients with a his-

tory of neurological disease, and objective continence rates of more than $60 \%$ can be achieved in highly selected patients.

\section{Statement of Ethics}

All procedures performed in our studies involving human participants were in accordance with the ethical standards of the institutional and national research committee and with the 1964 Helsinki declaration and its later amendments or comparable ethical standards.

\section{Conflict of Interest Statement}

Prof. Fisch, Dr. Dahlem, and Dr. Ludwig are consultants for Boston Scientific. All other authors have no conflicts to declare.

\section{Funding Sources}

The authors did not receive any funding.

\section{Author Contributions}

Valentin Maurer: manuscript writing and data analysis. Justus Stahlberg, Insa Schiffmann, Phillip Marks, Clemens M. Rosenbaum, Armin Soave, Malte W. Vetterlein, Christian P. Meyer, Silke Riechardt, and Margit Fisch: manuscript editing. Tim A. Ludwig: data collection, data analysis, and manuscript editing. Roland Dahlem: data analysis and manuscript editing.

\section{Informed Consent}

Informed consent was obtained from all individual participants included in the study.

\section{References}

Urol Int 2021;105:225-231 DOI: $10.1159 / 00051205$
Maurer et al.
1 Ficarra V, Novara G, Artibiani W, Cestari A, Galfano A, Graefen M. Retropubic, laparoscopic, and robot assisted radical prostatectomy: a systemic review and cumulative analysis of comparative studies. Eur Urol. 2009; 55:1037-63.

2 Hu JC, Elkin EP, Pasta DJ, Lubeck DP, Kattan MW, Carroll PR, et al. Predicting quality of life after radical prostatectomy: results from CaPSURE. J Urol. 2004;171(2 Pt 1):703-8.

3 Mandel P, Preisser F, Graefen M, Steuber T, Salomon G, Haese A, et al. High chance of late recovery of urinary and erectile function beyond 12 months after radical prostatectomy. Eur Urol. 2017;71(6):848-50. 
4 Burkhard FC, Bosch JL, Cruz F, Lemack GE, Nambiar AK, Thiruchelvam N. EAU guidelines on urinary incontinence in adults. EAU. 2018:53-7.

5 Brant WO, Erickson BA, Elliott SP, Powell C, Alsikafi N, McClung C, et al. Risk factors for erosion of artificial urinary sphincters: a multicenter prospective study. Urology. 2014; 84(4):934-8.

6 Lai HH, Boone TB. Complex artificial urinary sphincter revision and reimplantation cases: how do they fare compared to virgin cases? J Urol. 2012;187(3):951-5.

7 Winge K, Fowler CJ. Bladder dysfunction in parkinsonism: mechanisms, prevalence, symptoms, and management. Mov Disord. 2006;21(6):737-45.

8 Al-Qudah ZA, Yacoub HA, Souayah N. Disorders of the autonomic nervous system after hemispheric cerebrovascular disorders: an update. J Vasc Interv Neurol. 2015;8(4):4352.

9 Kapoor S, Bourdoumis A, Mambu L, Barua J. Effective management of lower urinary tract dysfunction in idiopathic Parkinson's disease. Int J Urol. 2013;20(1):79-84.
10 Araki I, Kuno S. Assessment of voiding dysfunction in Parkinson's disease by the international prostate symptom score. J Neurol Neurosurg Psychiatry. 2000;68(4):429-33.

11 Yeo L, Singh R, Gundeti M, Barua JM, Masood J. Urinary tract dysfunction in Parkinson's disease: a review. Int Urol Nephrol. 2012; 44(2):415-24.

12 Gupta A, Taly AB, Srivastava A, Thyloth M. Urodynamics post stroke in patients with urinary incontinence: is there correlation between bladder type and site of lesion? Ann Indian Acad Neurol. 2009;12(2):104-7.

13 Routh JC, Crimmins CR, Leibovich BC, Elliott DS. Impact of Parkinson's disease on continence after radical prostatectomy. Urology. 2006;68(3):575-7.

14 Schreiter F. Bulbar artificial sphincter. Eur Urol. 1985;11(5):294-9.

15 Staskin DS, Vardi Y, Siroky MB. Post-prostatectomy continence in the Parkinsonian patient: the significance of poor voluntary sphincter control. J Urol. 1988;140(1):117-8.
16 Blackett H, Walker R, Wood B. Urinary dysfunction in Parkinson's disease: a review. Parkinsonism Relat Disord. 2009;15(2):81-7.

17 Sakakibara R, Tateno F, Kishi M, Tsuyuzaki Y, Uchiyama T, Yamamoto T. Pathophysiology of bladder dysfunction in Parkinson's disease. Neurobiol Dis. 2012;46(3):565-71.

18 Campos-Sousa RN, Quagliato E, da Silva BB, de Carvalho RM, Ribeiro SC, de Carvalho DF. Urinary symptoms in Parkinson's disease: prevalence and associated factors. Arq Neuropsiquiatr. 2003;61(2B):359-63.

19 Trigo Rocha F, Gomes CM, Mitre AI, Arap S, Srougi M. A prospective study evaluating the efficacy of the artificial sphincter AMS 800 for the treatment of postradical prostatectomy urinary incontinence and the correlation between preoperative urodynamic and surgical outcomes. Urology. 2008;71(1):85-9.

20 Lai HH, Hsu EI, Boone TB. Urodynamic testing in evaluation of postradical prostatectomy incontinence before artificial urinary sphincter implantation. Urology. 2009;73(6): $1264-9$. 